\title{
Subjective age-of-acquisition norms for 4,640 verbs in Spanish
}

\author{
María Ángeles Alonso ${ }^{1,3} \cdot$ Emiliano Díez $^{2}$ - Angel Fernandez ${ }^{2}$
}

Published online: 22 October 2015

(C) Psychonomic Society, Inc. 2015

\begin{abstract}
Many studies have shown that how words are processed in a variety of language-related tasks is affected by their age of acquisition (AoA). Most AoA norms have been collected for nouns, a fact that limits the extent to which verb stimuli can be adequately manipulated and controlled in empirical studies. With the aim of increasing the number of verbs with AoA values in Spanish, 900 college students were recruited to provide subjective estimates for a total of 4,640 infinitive and reflexive forms. An AoA score for each verb was obtained by averaging the responses of the participants, and these norms were included, together with additional quantitative information (standard deviations, ranges, and $z$ scores), in a database that can be downloaded with this article as supplemental materials.
\end{abstract}

Keywords Age of acquisition - Verb norms · Word attributes · Spanish norms

Verbs represent a grammatical category with specific features that differentiate them from other categories such as nouns, adjectives, or adverbs. Whereas the commonly used nouns

Electronic supplementary material The online version of this article (doi:10.3758/s13428-015-0675-z) contains supplementary material, which is available to authorized users.

María Ángeles Alonso

maalonso@ull.es

1 Universidad de La Laguna, La Laguna, Spain

2 INICO, Universidad de Salamanca, Salamanca, Spain

3 Facultad de Psicologia, Universidad de La Laguna, Campus de Guajara, E-38205 La Laguna, Spain designate or identify entities such as objects, animals, places, or people, verbs are used to refer to actions or their results. In more formal terms, a verb may be defined as "a word (such as jump, think, happen, or exist) that is usually one of the main parts of a sentence and that expresses an action, an occurrence, or a state of being" ("Verb," 2015). Processing differences between verbs and other lexical units, mostly nouns, have captured the interest of cognitive and brain researchers and are currently under discussion with regard to what they demonstrate about the processing and representation of the grammatical and semantic features of language. But, independently of the ongoing theoretical discussions, the fact is that evidence of verb-noun dissociations can be traced back to the observations by Neapolitan philosopher Giambattista Vico (16681744) of a gentleman who, following stroke, could remember nouns but had forgotten verbs (reported by Denes \& Dalla Barba, 1998). Modern-day reports have also described verbnoun processing differences in brain-damaged patients in picture-naming tasks (e.g., Bi, Han, Shu, \& Caramazza, 2007; Damasio \& Tranel, 1993; Shapiro \& Caramazza, 2003), and further evidence of the dissociation in a variety of patients and tasks is provided in a review by Druks (2002) and in later neuropsychological studies. For example, Hillis et al. (2006) found a dissociation in the naming of objects and actions by patients with either progressive nonfluent aphasia or semantic dementia, with the latter showing more difficulties naming objects, and the former showing more difficulties naming actions. In addition, specific difficulties in processing verbs have been observed in patients with motor neuron disease (Bak \& Hodges, 2004), Parkinson's disease (Boulenger et al., 2008; Péran et al., 2003; RodríguezFerreiro, Menéndez, Ribacoba, \& Cuetos, 2009), and familial movement disorders (Bak et al., 2006). Differential processing of verbs is also found in the linguistic behavior of healthy individuals, who tend to show poorer memory performance 
and a later age of acquisition for verbs than for nouns (Gentner, 1981), although there may be language-specific exceptions (Tardif, 1996). Finally, in an effort to relate verb processing to specific brain mechanisms, researchers have used data from patients with brain damage and from healthy participants in a variety of tasks and paradigms, with most findings indicating that the processing of verbs and nouns may engage networks that are at least partially separable (see Vigliocco, Vinson, Druks, Barber, \& Cappa, 2011, for a wide review of relevant studies).

Apart from providing evidence of processing dissociations, the study of verbs has also led to theoretical advances and a better understanding of the development, use, and nature of the mental representations involved in discourse comprehension. For example, recent work by Ferguson, Graf, and Waxman (2014) illustrates how verbs that are present in the repertoire of very young children guide the process of attributing meaning to subsequently encountered novel words. Likewise, verb characteristics such as tense and aspect have been shown to modulate the extent to which the elements forming part of a representation are available for further processing in real-time discourse comprehension (Carreiras, Carriedo, Alonso, \& Fernandez, 1997) and to directly determine the construction and use of mental models in both children (Zhou, Crain, \& Zhan, 2014) and adults (Madden \& Zwaan, 2003).

If, as is argued above, significant knowledge about human cognition is gained through the systematic study of verb processing under a variety of conditions, much is to be gained by an effort to attain precise and thorough information about the intrinsic and relational characteristics of this type of words. Attempts to characterize lexical units in the recent past have resulted in a large collection of normative studies for English and other languages, mostly those used in America and Western European countries, with frequency traditionally being the lexical dimension of interest in a majority of studies. More recently, researchers have found a valuable source of information in a lexical attribute known as age of acquisition (AoA), an indicator of the average chronological age at which a word is first learned by users of a given language. Values for a set of words can be obtained through objective procedures - by interviewing children of different ages and asking them to recognize and name pictured objects corresponding to the words (e.g., Morrison, Chappell, \& Ellis, 1997). More frequently, reliable estimators are obtained by means of subjective procedures that demand from adults an estimation of the age at which they learned the words of interest (e.g., Kuperman, Stadhagen-Gonzalez, \& Brysbaert, 2012; Stadthagen-Gonzalez \& Davis, 2006).

AoA has proven to be a powerful predictor of lexical accessibility in a variety of tasks and contexts, as has been documented in extensive reviews by Juhasz (2005) and by Johnston and Barry (2006). In the specific case of verbs, studies have replicated the general finding of processing advantages for early-acquired exemplars in tasks requiring fast lexical access (for similar patterns in three different languages, see, e.g., Cuetos \& Alija, 2003; Kuperman et al., 2012; Morrison, Hirsh, \& Duggan, 2003; Schwitter, Boyer, Méot, Bonin, \& Laganaro, 2004), and there is also evidence of differential effects of AoA for nouns and verbs, with lexical decision being more strongly correlated with AoA in the case of verbs (Colombo \& Burani, 2002).

A sizable number of recent studies have reported AoA norms for various languages (e.g., Dutch, by Brysbaert, Stevens, De Deyne, Voorspoels, \& Storms, 2014; English, by Kuperman et al., 2012; German, by Schröder, Gemballa, Ruppin, \& Wartenburger, 2012; or Spanish, by Alonso, Fernandez, \& Díez, 2015), and a few have concentrated on obtaining values for verbs, usually small sets of infinitiveform labels of pictured actions (e.g., Masterson \& Druks, 1998). Most habitually, AoA databases provide indicators for larger mixed sets of words that include exemplars from the different grammatical categories, although nouns are always found to be the most numerous class when word-type information is provided. For example, Bird, Franklin, and Howard (2001) reported values obtained from British English speakers for a set of 2,645 words, 892 of which were verbs, and Schock, Cortese, Khanna, and Toppi (2012) provided values obtained from a sample of North American speakers of English for 3, 000 disyllabic words, with 456 of them corresponding to verbs. Other studies may have mentioned that verbs were part of the data set, but they failed to provide more specific information (e.g., Kuperman et al., 2012). The situation is similar in studies of other languages, with most data referring to nouns and databases insufficiently described in terms of the number of verbs included in the norms.

With regard to Spanish, AoA information on verbs is included in a report by Manzano, Piñeiro, and Pereira (1997) in which objective estimates were obtained from conversational exchanges with children 1 to 4 years of age in Cuba. In this database, there are 385 verbs in a global set of 1,259 words. Subsequent studies, until very recently, included almost exclusively nouns, many times corresponding to concrete objects like the ones depicted in the drawings of Snodgrass and Vanderwart (1980) or in similar entities (e.g., Cuetos, Ellis, \& Alvarez, 1999; Izura, Hernández-Muñoz, \& Ellis, 2005). Two recently published normative studies, based on subjective estimations by Spanish speakers in Spain, provide AoA indicators for 528 verbs (Davies, Barbón, \& Cuetos, 2013) and for 961 verbs (Alonso et al., 2015). The availability of this type of information for verbs in Spanish is, therefore, very similar to that in other languages of habitual use in cognitive studies, with information for a few hundred words being included in separate and diverse databases. In an attempt, first, to increase the size of the verb sample and, second, to construct a specific and easy-to-identify database for these type of words in Spanish, the present study was designed to obtain and report AoA subjective estimations for a set of 4,640 verbs. 


\section{Method}

\section{Participants}

A total of 900 undergraduate students at the Universidad de La Laguna, in Spain, participated in the study over a period of two consecutive academic years (2011-2012 and 2012-2013) in exchange for academic credit. All of them were native speakers of Spanish, $78 \%$ were women, and their ages ranged from 17 to 49 years $(M=20.54, S D=3.83)$. Forty-two of the participants (approximately $5 \%$ ) were self-declared bilinguals, with Spanish as their first language of use.

\section{Materials}

A sample of 4,640 verbs, in their infinitive or reflexive form, were selected as stimuli. They were drawn from other available lexical databases in Spanish, namely an oral frequency set (Alonso, Fernandez, \& Díez, 2011), two multi-index sets (Algarabel \& Sanmartín, 1985; Sebastián-Gallés, Martí, Carreiras, \& Cuetos, 2000), and a set of descriptors for action pictures (Cuetos \& Alija, 2003). The verbs varied widely in features such as number of letters (ranging from 2 to 16) or frequency of use (ranging from 0.32 to 1849 per million in Alonso et al., 2011).

\section{Procedure}

The pool of verbs was randomly distributed into 18 distinct sets, each containing either 257 or 258 verbs, with the aim of presenting a manageable group of verbs to each participant. With the aim of minimizing order effects, five different random orders of the items were established for each set, with each order being printed in a booklet and presented to ten participants. As a result, each verb in the subset was presented to and rated by 50 participants. The first page of the booklet included a simple description of the task to be performed, asking participants to provide, in writing, the age at which they thought they had learned the meaning of each particular verb in the set. Participants were explicitly told that the words were verbs in infinitive and reflexive form. Following a procedure frequently used by recent researchers in the area (see Brysbaert et al., 2014; Stadthagen-Gonzalez \& Davis, 2006), a predefined age scale was not used, and participants were required to directly enter the number corresponding to a particular age, in years. In subsequent pages, the verbs assigned to the booklet were printed in uppercase letters and arranged in three columns per page. Participants were instructed to do the verbs in the left column first, starting from the top and proceeding to the bottom, writing a number in the blank space provided by each verb, without blank responses, and marking with an " $\mathrm{X}$ " verbs that they did not know. The same was to be done next with the list of verbs in the middle column, and then with the right column, and the procedure was to be repeated until the last page in the booklet was completed.

\section{Results}

The scores provided by each participant to each stimulus (a total of 50) were entered into a computerized spreadsheet. The mean, standard deviation, and $z$ scores were computed for each verb on the basis of the provided responses. ${ }^{1}$ The spreadsheet-format file accompanying this report (AoA verbs.xls) contains these data and additional information for each verb entry. The verbs are listed in alphabetical order, each followed by six columns containing the descriptive values of interest. Provided in the columns are, in this order, the average AoA of the verb, the corresponding standard deviation, the minimum value assigned to the verb, the maximum value assigned to it, the number of participants reporting a value, and the item's $z$ score (the average of the participants' $z$ scores for that item).

The distribution of the obtained AoA mean scores ranged from 1 to 31, and it did not conform to normality, as evidenced by a Kolmogorov-Smirnov test $(D=0.51, p<.05)$, with a skewness of $-0.32(S E=0.03)$ and a kurtosis value of -0.62 $(S E=0.06)$. The reliability of the AoA mean scores was computed after substituting 0 values for the Xs indicating unknown verbs. The statistical analyses showed high scores when assessed by the Guttman split-half coefficient $(r=.98$, $p<.001)$ or by Cronbach's test $(\alpha=.96, p<.001)$.

The validity of the present normative data was assessed by performing correlational analyses among the scores in this study and other subjective AoA indicators available in Spanish. As is shown in Table 1, the correlations were significant and high. Additional analyses exploring the correlations of the present scores with lexical performance measures showed that, as would be expected from other studies in Spanish (e.g., Alonso et al., 2015), the AoA of a verb was a significant predictor of its lexical decision time $(r=.58, N=$ 536) when tests were run on the data provided by GonzálezNosti, Barbón, Rodríguez-Ferreiro, and Cuetos (2013), although AoA was not systematically related to the naming time ( $r=-.02, N=528$ ) when tests were run on the data provided by Davies et al. (2013). Finally, the expected negative correlations between AoA and several estimators of frequency were found: $r=-.50$ in the case of oral frequency (Alonso et al., 2011), $r=-.54$ in the case of printed frequency (Sebastián-

\footnotetext{
${ }^{1}$ The number of age responses to each verb varied. Although most verbs were known to a majority of the participants ( $78 \%$ of verbs were assigned an age score by at least $90 \%$ of the respondents), not all participants knew all of the verbs they had to judge. Still, substantial information was acquired for the great majority of items, and $94.5 \%$ of the verbs were assigned an age of acquisition by a minimum sample of 25 participants.
} 
Table 1 Correlations between the present age-of-acquisition (AoA) indexes and those reported for shared verbs in three other Spanish databases

\begin{tabular}{lll}
\hline & Subjective AoA & \\
\hline Study & Shared Verbs & $r$ \\
Davies, Barbón, \& Cuetos (2013) & 528 & $.915^{* *}$ \\
Cuetos \& Alija (2003) & 91 & $.835^{* *}$ \\
Alonso, Fernandez, \& Díez (2015) & 380 & $.925^{* *}$ \\
${ }^{* *} p<.01$ & &
\end{tabular}

Gallés et al., 2000), and $r=-.57$ in the case of subtitle frequency (Cuetos, González-Nosti, Barbón, \& Brysbaert, 2011). It is interesting that these correlations, for verbs, are noticeably larger that those previously reported for a similar but more heterogeneous data set composed of words of different kinds (see Alonso et al., 2015), suggesting that many early-acquired verbs (e.g., to speak, to eat) continue to be used into adulthood, whereas it is likely that a larger proportion of nouns that are early-acquired (e.g., dragon or fairy) decay in their use across development.

\section{Discussion}

Subjective ratings reflecting the age of word acquisition were obtained for a large set of Spanish verbs, an effort aimed at improving both the quantity and quality of research-relevant information about verbal materials in Spanish. The contribution in quantitative terms is apparent in the fact that the present norms contain about four times more verbs than all of the previously collected norms for Spanish taken together, and when added to the set of AoA norms recently reported by Alonso et al. (2015), bring to more than 11,000 the number of different words for which this type of rating is now available in Spanish.

Besides the increment in the amount of information available for verbs, the newly available information is also of relevance because it will potentially enable the development of interesting lines of research. It surpasses the scope of this report to do an extensive analysis of the multiple ways in which the data provided could be used in further theoretical elaboration and empirical developments, but the few ideas that follow could be taken as illustrations of the possibilities awaiting interested researchers.

As an example, a very exploratory attempt to relate AoA scores to the semantic classification of Spanish verbs available in the ADESSE database (Vaamonde, González Domínguez, \& García-Miguel, 2010) showed that earlier AoA values tend to belong to the "material" macroclass (i.e., not mental) - a supraordinate category including several subclasses of physical processes, such as those related to ingestion, body care, body contact, and so forth. However, higher AoA values correspond mostly to verbs in the "relational" macroclass (i.e., attribution and possession), a set in which the verbs denote property, time, or transference. If systematic relationships of this kind can be found and more precisely characterized, researchers could document how the AoA of certain language elements, such as verbs, could become a relevant variable in accounting for language acquisition patterns, the development of knowledge structures, or the early mapping of body-object interactions. In this vein, Maouene, Hidaka, and Smith (2008) have documented that early-acquired verbs tend to refer to actions that are practicable with concrete body parts, such as the mouth and the hands.

It is also worth noting that recent research on verb use by Spanish-speaking participants with brain pathologies such as Parkinson's disease (Cardona et al., 2014; Herrera, Rodríguez-Ferreiro, \& Cuetos, 2012) is contributing to understand the lexical and semantic organization of verbs through the study of patterns of differential degradation. Because AoA has been demonstrated to modulate verb processing in both unimpaired and language-impaired populations (e.g., Bradley, Davies, Parris, Su, \& Weekes, 2006; De Bleser \& Kauschke, 2003) it is reasonable to expect informative AoA modulation of verb use in specific pathologies, with differential patterns being related to the prevailing difficulties (perceptual, motor, etc.).

Finally, attention to verb processing is also likely to be of importance in developing and testing new theoretical approaches to language understanding and production. For example, because of the special connection of verbs to "action" meanings, a theoretical perspective such as the embodiment theory of language and cognition (de Vega \& Glenberg, 2008; Pecher \& Zwaan, 2005) is already revealing substantial critical evidence about the representation, comprehension, and retention of action information in studies involving the observation and manipulation of verbs. Glenberg, Sato, and Cattaneo (2008) have shown that the processing of sentences that include transfer verbs (such as give, throw, bring, etc.) is affected by the direction of preceding movements of the reader's arm. Shebani and Pulvermüller (2013) found that motor actions during a retention interval can interfere with the short-term recall of verbs if they are specifically related in meaning to the body parts involved in the actions. The claim by embodiment theorists that meaning results from activity in brain areas related to action, perception, and emotion (Glenberg, 2010) is related to those findings showing that, in children, the processing of early-acquired verbs triggers effector-specific activation patterns in motor and premotor circuits in the cortex (James \& Maouene, 2009).

For both empirical and theoretical reasons, then, characterizing verbs and investigating the way in which a critical feature, such as AoA, affects how they are processed should be a goal of researchers interested in language processing. 
Author note This work was supported by Ministerio de Economía y Competitividad (Grant No. PSI2013-42872-P) and by Universidad de Salamanca (Planes Propios de Apoyo a la Investigación, 2013 and 2014). Suggestions by an anonymous reviewer on an earlier version of the manuscript are thankfully acknowledged.

\section{References}

"Verb." (2015). In Merriam-Webster's online dictionary. Retrieved March 9, 2015, from www.merriam-webster.com/dictionary/verb

Algarabel, S., \& Sanmartín, J. (1985). BASPAL: descripción de la base computerizada de palabras de la Universidad de Valencia. Psicológica, 6, 189-200.

Alonso, M. A., Fernandez, A., \& Díez, E. (2011). Oral frequency norms for 67,979 Spanish words. Behavior Research Methods, 43, 449458. doi:10.3758/s13428-011-0062-3

Alonso, M. A., Fernandez, A., \& Díez, E. (2015). Subjective age-ofacquisition norms for 7,039 Spanish words. Behavior Research Methods, 47, 268-274. doi:10.3758/s13428-014-0454-2

Bak, T. H., \& Hodges, J. R. (2004). The effects of motor neurone disease on language: futher evidence. Brain and Language, 89, 354-361. doi:10.1016/S0093-934X(03)00357-2

Bak, T. H., Yancopoulou, D., Nestor, P. J., Xuereb, J. H., Spillantini, M. G., Pulvermüller, F., \& Hodges, J. R. (2006). Clinical, imaging and pathological correlates of a hereditary deficit in verb and action processing. Brain, 129, 321-332. doi:10.1093/brain/awh701

Bi, Y., Han, Z., Shu, H., \& Caramazza, A. (2007). Nouns, verbs, objects, actions, and the animate/inanimate effect. Cognitive Neuropsychology, 24, 485-504. doi:10.1080/02643290701502391

Bird, H., Franklin, S., \& Howard, D. (2001). Age of acquisition and imageability ratings for a large set of words, including verbs and function words. Behavior Research Methods, Instruments, \& Computers, 33, 73-79. doi:10.3758/BF03195349

Boulenger, V., Mechtouff, L., Thobois, S., Broussolle, E., Jeannerod, M., \& Nazir, T. A. (2008). Word processing in Parkinson's disease is impaired for action verbs but not for concrete nouns. Neuropsychologia, 46, 743-756. doi:10.1016/j.neuropsychologia. 2007.10.007

Bradley, V., Davies, R., Parris, B., Su, I. F., \& Weekes, B. S. (2006). Age of acquisition effects on action naming in progressive fluent aphasia. Brain and Language, 99, 117-118. doi:10.1016/j.bandl.2006.06. 073

Brysbaert, M., Stevens, M., De Deyne, S., Voorspoels, W., \& Storms, G. (2014). Norms of age of acquisition and concreteness for 30,000 Dutch words. Acta Psychologica, 150, 80-84. doi:10.1016/j. actpsy.2014.04.010

Cardona, J. F., Kargieman, L., Sinay, V., Gershanik, O., Gelormini, C., Amoruso, L., \& Ibáñez, A. (2014). How embodied is action language? Neurological evidence from motor diseases. Cognition, 131, 311-322. doi:10.1016/j.cognition.2014.02.001

Carreiras, M. C., Carriedo, N., Alonso, M. A., \& Fernandez, A. (1997). The role of verb tense and verb aspect in the foregrounding of information in reading. Memory \& Cognition, 25, 438-446. doi: 10.3758/BF03201120

Colombo, L., \& Burani, C. (2002). The influence of age of acquisition, root frequency, and context availability in processing nouns and verbs. Brain and Language, 81, 398-411. doi:10.1006/brln.2001. 2533

Cuetos, F., \& Alija, M. (2003). Normative data and naming times for action pictures. Behavior Research Methods, Instruments, \& Computers, 35, 168-177. doi:10.3758/BF03195508

Cuetos, F., Ellis, A. W., \& Alvarez, B. (1999). Naming times for the Snodgrass and Vanderwart pictures in Spanish. Behavior Research
Methods, Instruments, \& Computers, 31, 650-658. doi:10.3758/ BF03200741

Cuetos, F., González-Nosti, M., Barbón, A., \& Brysbaert, M. (2011). SUBTLEX-ESP: Spanish word frequencies based on film subtitles. Psicológica, 32, 133-143.

Damasio, A.R., \& Tranel, D. (1993). Nouns and verbs are retrieved with differently distributed neural systems. Proceedings of the National Academy of Sciences, 90, 4957-4960.

Davies, R., Barbón, A., \& Cuetos, F. (2013). Lexical and semantic age-ofacquisition effects on word naming in Spanish. Memory \& Cognition, 41, 297-311. doi:10.3758/s13421-012-0263-8

De Bleser, R., \& Kauschke, C. (2003). Acquisition and loss of nouns and verbs: parallel or divergent patterns? Journal of Neurolinguistics, 16, 213-229. doi:10.1016/S0911-6044(02)00015-5

De Vega, M., \& Glenberg, A. M. (Eds.). (2008). Symbols and embodiment: debates on meaning and cognition. New York, NY: Oxford University Press.

Denes, G., \& Dalla Barba, G. (1998). G. B. Vico, precursor of cognitive neuropsychology? The first reported case of noun-verb dissociation following brain damage. Brain and Language, 62, 29-33.

Druks, J. (2002). Verbs and nouns - a review of the literature. Journal of Neurolinguistics, 15, 289-315.

Ferguson, B., Graf, E., \& Waxman, S. R. (2014). Infants use known verbs to learn novel nouns: evidence from 15- and 19-month-olds. Cognition, 131, 139-146. doi:10.1016/j.cognition.2013.12.014

Gentner, D. (1981). Some interesting differences between verbs and nouns. Cognitive and Brain Theory, 4, 161-178.

Glenberg, A. M. (2010). Embodiment as a unifying perspective for psychology. Wiley Interdisciplinary Reviews: Cognitive Science, 1, 586-596. doi:10.1002/wcs.55

Glenberg, A. M., Sato, M., \& Cattaneo, L. (2008). Use-induced motor plasticity affects the processing of abstract and concrete language. Current Biology, 18, R290-R291.

González-Nosti, M., Barbón, A., Rodríguez-Ferreiro, J., \& Cuetos, F. (2013). Effects of the psycholinguistic variables on the lexical decision task in Spanish: a study with 2,765 words. Behavior Research Methods, 46, 517-525. doi:10.3758/s13428-013-0383-5

Herrera, E., Rodríguez-Ferreiro, J., \& Cuetos, F. (2012). The effect of motion content in action naming by Parkinson's disease patients. Cortex, 48, 900-904. doi:10.1016/j.cortex.2010.12.007

Hillis, A. E., Heidler-Gary, J., Newhart, M., Chang, S., Ken, L. M., \& Bak, T. H. (2006). Naming and comprehension in primary progressive aphasia: the influence of grammatical word class. Aphasiology, 20, 246-256. doi:10.1080/02687030500473262

Izura, C., Hernández-Muñoz, N., \& Ellis, A. W. (2005). Category norms for 500 Spanish words in five semantic categories. Behavior Research Methods, 37, 385-397. doi:10.3758/BF03192708

James, K. H., \& Maouene, J. (2009). Auditory verb perception recruits motor systems in the developing brain: an fMRI investigation. Developmental Science, 12, F26-F34. doi:10.1111/j.1467-7687. 2009.00919.x

Johnston, R. A., \& Barry, C. (2006). Age of acquisition and lexical processing. Visual Cognition, 13, 789-845. doi:10.1080/ 13506280544000066

Juhasz, B. J. (2005). Age of acquisition effects in word and picture identification. Psychological Bulletin, 131, 684-712. doi:10.1037/00332909.131.5.684

Kuperman, V., Stadthagen-Gonzalez, H., \& Brysbaert, M. (2012). Ageof-acquisition ratings for 30,000 English words. Behavior Research Methods, 44, 978-990. doi:10.3758/s13428-012-0210-4

Madden, C. J., \& Zwaan, R. A. (2003). How does verb aspect constrain event representations? Memory \& Cognition, 31, 663-672. doi:10. 3758/BF03196106

Manzano, M., Piñeiro, A., \& Pereira, M. (1997). Frecuencia de uso y edad de adquisición de palabras producidas por niños entre 11 y 49 meses de edad. Revista Cubana de Psicología, 14, 193-207. 
Maouene, J., Hidaka, S., \& Smith, B. L. (2008). Body parts and earlylearned verbs. Cognitive Science, 32, 1200-1216. doi:10.1080/ 03640210802019997

Masterson, J., \& Druks, J. (1998). Description of a set of 164 nouns and 102 verbs matched for printed word frequency, familiarity and ageof-acquisition. Journal of Neurolinguistics, 11, 331-354.

Morrison, C. M., Chappell, T. D., \& Ellis, A. W. (1997). Age of acquisition norms for a large set of object names and their relation to adult estimates and other variables. Quarterly Journal of Experimental Psychology, 50A, 528-559. doi:10.1080/027249897392017

Morrison, C. M., Hirsh, K. W., \& Duggan, G. B. (2003). Age of acquisition, ageing, and verb production: normative and experimental data. Quarterly Journal of Experimental Psychology, 56A, 705730. doi:10.1080/02724980244000594

Pecher, D., \& Zwann, R. A. (Eds.). (2005). Grounding cognition: the role of perception and action in memory, language, and thinking. New York, NY: Cambridge University Press.

Péran, P., Rascol, O., Démonet, J.-F., Celsis, P., Nespoulous, J.-L., Dubois, B., \& Cardebat, D. (2003). Deficit of verb generation in nondemented patients with Parkinson's disease. Movement Disorders, 18, 150-156.

Rodríguez-Ferreiro, J., Menéndez, M., Ribacoba, R., \& Cuetos, F. (2009). Action naming is impaired in Parkinson disease patients. Neuropsychologia, 47, 3271-3274. doi:10.1016/j.neuropsychologia. 2009.07.007

Schock, J., Cortese, M. J., Khanna, M., \& Toppi, S. (2012). Age of acquisition estimates for 3,000 disyllabic words. Behavior Research Methods, 44, 971-977. doi:10.3758/s13428-012-0209-х

Schröder, A., Gemballa, T., Ruppin, S., \& Wartenburger, I. (2012). German norms for semantic typicality, age of acquisition, and concept familiarity. Behavior Research Methods, 44, 380-394. doi:10. 3758/s13428-011-0164-y

Schwitter, V., Boyer, B., Méot, A., Bonin, P., \& Laganaro, M. (2004). French normative data and naming times for action pictures. Behavior Research Methods, Instruments, \& Computers, 36, 564576. doi:10.3758/BF03195603
Sebastián-Gallés, N., Martí, A., Carreiras, M., \& Cuetos, F. (2000). LEXESP: Una base de datos informatizada del español. Barcelona, Spain: Editions Universitat de Barcelona.

Shapiro, K., \& Caramazza, A. (2003). Grammatical processing of nouns and verbs in left frontal cortex? Neuropsychologia, 41, 1189-1198. doi:10.1016/S0028-3932(03)00037-X

Shebani, Z., \& Pulvermüller, F. (2013). Moving the hands and feet specifically impairs working memory for arm- and leg-related action words. Cortex, 49, 222-231. doi:10.1016/j.cortex.2011. 10.005

Snodgrass, J. G., \& Vanderwart, M. (1980). A standardized set of 260 pictures: norms for name agreement, image agreement, familiarity, and visual complexity. Journal of Experimental Psychology, 6, 174 215. doi:10.1037/0278-7393.6.2.174

Stadthagen-Gonzalez, H., \& Davis, C. J. (2006). The Bristol norms for age of acquisition, imageability, and familiarity. Behavior Research Methods, 38, 598-605. doi:10.3758/BF03193891

Tardif, T. (1996). Nouns are not always learned before verbs: evidence from mandarin speakers' early vocabularies. Developmental Psychology, 32, 492-504.

Vaamonde, G., González Domínguez, F., \& García-Miguel, J. M. (2010). ADESSE: A database with syntactic and semantic annotation of a corpus of Spanish. In N. Calzolari, K. Choukri, B. Maegaard, J. Mariani, J. Odijk, \& D. Tapias (Eds.), Proceedings of the seventh international conference on language resources and evaluation (LREC) (pp. 1903-1910). European Language Resources Association: Paris, France.

Vigliocco, G., Vinson, D. P., Druks, J., Barber, H., \& Cappa, S. F. (2011). Nouns and verbs in the brain: a review of behavioural, electrophysiological, neuropsychological and imaging studies. Neuroscience \& Biobehavioral Reviews, 35, 407-426. doi:10.1016/j.neubiorev. 2010.04.007

Zhou, P., Crain, S., \& Zhan, L. (2014). Grammatical aspect and event recognition in children's online sentence comprehension. Cognition, 133, 262-276. doi:10.1016/j.cognition.2014.06.018 